\title{
PNEUMONECTOMY FOR MALIGNANT DISEASE: FACTORS AFFECTING EARLY MORBIDITY AND MORTALITY
}

Alain Bernard, MD

Claude Deschamps, MD

Mark S. Allen, MD

Daniel L. Miller, MD

Victor F. Trastek, MD

Gregory D. Jenkins, BS ${ }^{\mathrm{b}}$

Peter C. Pairolero, $\mathrm{MD}^{\mathrm{a}}$
Objective: The purpose of this report is to analyze factors affecting morbidity and mortality after pneumonectomy for malignant disease.

Methods: We retrospectively reviewed the cases of all patients who underwent pneumonectomy for malignancy at the Mayo Clinic. Between January 1, 1985, and September 30, 1998, 639 patients (469 men and 170 women) were identified. Median age was 64 years (range 20 to 86 years). Indication for pneumonectomy was primary lung cancer in 607 (95.0\%) patients and metastatic disease in $32(5.0 \%)$. Factors affecting morbidity and mortality were analyzed by univariate and multivariate analysis.

Results: Cardiopulmonary complications occurred in 245 patients $38.3 \%$; 95\% confidence interval $34.6 \%-42.2 \%)$. Factors adversely affecting morbidity with univariate analysis included age $(P<.0001)$, male sex $(P=.04)$, associated respiratory $(P=.02)$ or cardiovascular disease $(P<.0001)$, cigarette smoking $(P=.02)$, decreased vital capacity $(P=.01)$, forced expiratory volume in 1 second $(P<.0001)$, forced vital capacity $(P=.002)$, diffusion capacity of the lung to carbon monoxide $(P=.005)$, oxygen saturation $(P<.05)$, arterial $\mathrm{Po}_{2}(P=.007)$, preoperative radiation $(P=.02)$, bronchial stump reinforcement $(P=.007)$, crystalloid infusion $(P=.01)$, and blood transfusion $(P=.02)$. Factors adversely affecting morbidity with multivariate analysis included age $(P=.0001)$, associated cardiovascular disease $(P=.001)$, and bronchial stump reinforcement $(P=.0005)$. There were 45 deaths $(7.0 \%$; 95\% confidence intervals $5.2 \%-9.3 \%)$. Factors adversely affecting mortality with univariate analysis included associated cardiovascular $(P<.0001)$ or hematologic disease $(P<.005)$, lower preoperative serum hemoglobin level $(P=.004)$, preoperative chemotherapy $(P=.01)$, decreased diffusion capacity of lung to carbon monoxide $(P=.002)$, right pneumonectomy $(P=.0006)$, extended resection $(P=.04)$, bronchial stump reinforcement $(P=.007)$, and crystalloid infusion $(P=.01)$. Factors affecting mortality with multivariate analysis included hematologic disease $(P=.01)$, lower preoperative serum hemoglobin $(P=.003)$, and completion pneumonectomy $(P=.01)$.

Conclusion: Multiple factors adversely affected morbidity and mortality after pneumonectomy for malignant disease. Appropriate selection and meticulous perioperative care are paramount to minimize risks in those patients who require pneumonectomy. (J Thorac Cardiovasc Surg 2001;121:1076-82)
From the Division of General Thoracic Surgery a and the Section of Biostatistics, b Mayo Clinic and Mayo Foundation, Rochester, Minn.

Read at the Eightieth Annual Meeting of The American Association for Thoracic Surgery, Toronto, Ontario, Canada, April 30-May 3, 2000.

Copyright (C) 2001 by The American Association for Thoracic Surgery

$0022-5223 / 2001 \$ 35.00+0 \quad \mathbf{1 2 / 6 / 1 1 4 3 5 0}$

doi:10.1067/mtc.2001.114350

1076
Dneumonectomy for malignant disease is associated with significant morbidity and mortality. ${ }^{1,2}$ Little information, however, is known regarding predisposing factors. The purpose of this review was to evaluate our results in patients undergoing pneumonectomy for cancer.

\section{Patients and methods}

Between January 1, 1985, and September 30, 1998, 639 patients underwent elective pneumonectomy for malignancy 
Table I. Preoperative pulmonary function values in 639 patients undergoing pneumonectomy

\begin{tabular}{lcc}
\hline Variable & Median (range) & No. of patients \\
\hline TLC (\% predicted) & $98(45-152)$ & 348 \\
VC (\% predicted) & $88(36-151)$ & 486 \\
FVC (\% predicted) & $84(4-151)$ & 529 \\
FEV $1 \%$ predicted) & $73(27-152)$ & 543 \\
RV (\% predicted) & $111(52-258)$ & 348 \\
DLCO, exercise (\% predicted) & $76(26-99)$ & 388 \\
$\mathrm{O}_{2}$ saturation, rest (\%) & $95(82-100)$ & 356 \\
$\mathrm{O}_{2}$ saturation, exercise (\%) & $93(80-99)$ & 345 \\
$\mathrm{PaO}_{2}$ (mm Hg) & $75(50-100)$ & 79 \\
$\mathrm{PaCO}_{2}$ (mm Hg) & $37(31-54)$ & 79 \\
\hline
\end{tabular}

$T L C$, Total lung capacity; $V C$, vital capacity; $F V C$, forced vital capacity; $F E V_{1}$, forced expiratory volume in 1 second; $R V$, residual volume; $D L C O$, diffusion capacity of lung to carbon monoxide; $\mathrm{O}_{2}$, oxygen; $\mathrm{PaO}_{2}$, arterial partial pressure of oxygen; $\mathrm{PaCO}_{2}$, arterial partial pressure of carbon dioxide.

at the Mayo Clinic in Rochester, Minnesota. The records of these patients were analyzed for age, sex, preoperative conditions, pulmonary function and gas exchange tests, indications for operation, preoperative clinical stage, adjuvant treatment, extent of operation, morbidity, and operative mortality. Morbidity included all complications occurring during hospitalization only. Postoperative respiratory failure was considered to be present if any of the following criteria were present: mechanical ventilatory support greater than 24 hours, positive airway pressure mask required at any time, or supplemental oxygen required after hospital dismissal. Retained secretions were considered to be present when bronchoscopy was necessary for removal. Mortality (operative deaths) included both those patients who died within the first 30 days after the operation and those who died later but during the same hospitalization.

The primary end points of analysis were morbidity and mortality. The effects of risk factors on these end points were evaluated with both univariate and multivariate analysis. Risk factors represented by continuous variables were assessed by use of 2-sample $t$ tests $^{3}$ when the data were approximately normal and by rank sum tests ${ }^{4}$ when the data were found to be not sufficiently gaussian. The effects of categorical variable risk factors were evaluated by means of $\chi^{2}$ tests $^{5}$ and the Fisher exact tests. ${ }^{6}$ Multiple logistic regression ${ }^{7}$ was used during multivariate analysis to simultaneously evaluate the effects of risk factors. Specifically, stepwise selection was used to identify significant predictors. Variables found to be significant in the logistic regression models were reported by means of odds ratios with $95 \%$ confidence intervals (CI). All statistical tests were 2-sided. All analyses were conducted with the SAS statistical program (SAS Institute Inc, Cary, NC).

Clinical findings. A total of 639 patients (469 men and 170 women) were evaluated. Median age was 64 years and ranged from 20 to 86 years. Indication for pneumonectomy was primary lung cancer in 607 (95.0\%) patients and metastatic cancer in $32(5.0 \%)$. Primary lung cancers were classified as
Table II. Complications in 276 (43.2\%) of the 639 patients undergoing pneumonectomy

\begin{tabular}{lc}
\hline Complications & No. $(\%)$ \\
\hline Respiratory & $260(40.7)$ \\
Respiratory failure & $102(16.0)$ \\
Retention of secretions & $86(13.5)$ \\
Pneumonia & $65(10.2)$ \\
PPPE & $7(1.1)$ \\
Cardiovascular & $190(29.7)$ \\
$\quad$ Arrhythmia $\quad 167(26.1)$ \\
$\quad$ Atrial fibrillation & $137(21.4)$ \\
$\quad$ Supraventricular tachycardia & $28(4.4)$ \\
$\quad$ Ventricular & $7(1.1)$ \\
Congestive/right heart failure & $19(3.0)$ \\
Acute myocardial infarction & $4(0.6)$ \\
Empyema & $36(5.6)$ \\
Bronchopleural fistula & $25(3.9)$ \\
Hemothorax & $10(1.6)$ \\
Wound infection & $9(1.4)$ \\
Pulmonary embolus & $7(1.1)$ \\
Cerebrovascular accident & $6(1.0)$ \\
Chylothorax & $2(0.3)$ \\
Esophagopleural fistula & $2(0.3)$ \\
Other & $37(5.8)$ \\
\hline
\end{tabular}

PPPE, Postpneumonectomy pulmonary edema.

stage IA in 51 patients, IB in 72 , IIA in 135 , IIB in 6 , IIIA in 302 , and stage IIIB in 41. Cell type included squamous cell carcinoma in 354 patients, adenocarcinoma in 169, large cell undifferentiated in 44, bronchoalveolar in 16, carcinoid in 11, and other in 13 . The site of origin of metastatic disease was a soft tissue sarcoma in 13 patients, osteogenic sarcoma in 5, melanoma in 3 , lymphoma in 3 , breast carcinoma in 2 , and other in 6 .

Associated conditions were present in 305 (47.7\%) patients and included chronic obstructive pulmonary disease in 183 $(28.6 \%)$ (Table I), coronary artery disease in $84(13.1 \%)$, cardiac arrhythmia in $58(9.1 \%)$, diabetes mellitus in $54(8.5 \%)$, alcoholism in $38(5.9 \%)$, asthma in $29(4.5 \%)$, valvular heart disease in $25(3.9 \%)$, corticosteroid use in 25 (3.9\%), congestive heart failure in $11(1.7 \%)$, hematologic disease in 11 $(1.7 \%)$, chronic renal failure in $5(0.1 \%)$, and other in 71 $(11.1 \%)$. The median serum hemoglobin value was $13.4 \mathrm{~g} / \mathrm{dL}$ (range 7.4-17.5 g/dL).

Seventy-five $(11.7 \%)$ patients had a history of nonpulmonary malignancy. A total of $578(90.5 \%)$ patients were chronic cigarette smokers (median 50 pack-years; range 7-96 pack-years), and 186 (29.1\%) of these patients were smoking in the 8 weeks preceding pneumonectomy. Eighteen patients $(2.8 \%$ ) lost a median of $8.2 \mathrm{~kg}$ (range $1.8-27.3 \mathrm{~kg}$ ) before pneumonectomy. Median body mass index was $25.9 \mathrm{~kg} / \mathrm{m}^{2}$ (range $15.9-60.4 \mathrm{~kg} / \mathrm{m}^{2}$ ).

Sixty-two patients $(9.7 \%)$ had a prior lung resection; 57 had 1 previous resection, 3 had 2 resections, and 2 had 3 resections. Previous pulmonary resections included lobectomy in 37 patients, wedge or segmentectomy in 29 , and bilobectomy in 3. Sixty-three $(9.9 \%)$ patients had preopera- 
Table III. Variables that adversely affected postoperative cardiopulmonary morbidity with univariate analysis

\begin{tabular}{|c|c|}
\hline Significant adverse effect & $\mathrm{P}$ value \\
\hline Increased age & $<.0001$ \\
\hline Male sex & .04 \\
\hline Respiratory disease & .02 \\
\hline Cardiovascular disease & $<.0001$ \\
\hline Smoking (pack-years) & .02 \\
\hline Decreased VC (\% predicted) & .01 \\
\hline Decreased $\mathrm{FEV}_{1}(\%$ predicted $)$ & $<.0001$ \\
\hline Decreased FVC (\% predicted) & .002 \\
\hline Decreased DLCO, exercise (\% predicted) & .005 \\
\hline Decreased $\mathrm{O}_{2}$ saturation, rest $(\%)$ & .03 \\
\hline Decreased $\mathrm{O}_{2}$ saturation, exercise $(\%)$ & .0005 \\
\hline Decreased $\mathrm{PaO}_{2}(\mathrm{~mm} \mathrm{Hg})$ & .007 \\
\hline Preoperative radiation & .02 \\
\hline Reinforcement of bronchial stump & .007 \\
\hline Parenteral crystalloid, first $24 \mathrm{~h}$ & .01 \\
\hline Parenteral crystalloid, first $12 \mathrm{~h}$ & .01 \\
\hline Total units of blood transfusions & .02 \\
\hline
\end{tabular}

$V C$, Vital capacity; $F E V_{l}$, forced expiratory volume in 1 second; $F V C$, forced vital capacity; $D L C O$, diffusion capacity of the lung to carbon monoxide; $\mathrm{O}_{2}$, oxygen; $\mathrm{PaO}_{2}$, arterial partial pressure of oxygen.

tive adjuvant therapy, including chemotherapy within 3 months of pneumonectomy in 21 , radiation in 18 , and a combination of both in 24 . Two hundred eighty-five (44.6\%) patients had mediastinoscopy before pneumonectomy.

Pneumonectomy was on the left in $333(52.1 \%)$ patients and on the right in 306 (47.9\%). An extended resection was performed in $290(45.4 \%)$ patients, including intrapericardial dissection in $213(33.3 \%)$, en bloc parietal pleura resection in $77(12.1 \%)$, en bloc chest wall resection in $67(10.5 \%)$, a portion of left atrium in $20(3.1 \%)$, carinal resection in 20 (3.1\%), diaphragm in $12(1.9 \%)$, superior vena cava in 12 $(1.9 \%)$, esophageal muscle in $8(1.3 \%)$, thoracic aortic adventitia in $6(1.0 \%)$, and right atrium, vertebral fascia, spine, and main pulmonary artery in $1(0.2 \%)$ each. Extracorporeal circulation was used in $2(0.3 \%)$ patients. Completion pneumonectomy was performed in 57 (8.8\%) patients. A complete mediastinal lymph node dissection was performed in $618(9.0 \%)$ patients. The bronchus was closed with a stapling device in $588(92.0 \%)$ patients and handsutured in $51(8.0 \%)$. The bronchial stump was reinforced in $117(18.3 \%)$ patients and included muscle in 59, parietal pleura in 40 , and pericardium in 18 . The serratus anterior muscle was used to reinforce the bronchial stump in 45 patients, latissimus dorsi in 12 , and a combination of both in 2. Tube thoracostomy was used to balance the mediastinum in 628 patients. The chest tube was removed immediately after pneumonectomy in 499 patients, during the first postoperative day in 122 , the second postoperative day in 5 , and the third postoperative day in 2 .

Eighty-six (13.5\%) patients had at least one intraoperative blood transfusion (median 2 units, range 1-37 units), and 33 $(5.2 \%)$ had at least one transfusion within the first 24 postop-
Table IV. Variables that adversely affected postoperative cardiopulmonary morbidity with multivariate analysis

\begin{tabular}{lccc}
\hline Variable & P value & OR & $95 \%$ CI \\
\hline Increased age & .0001 & 1.036 & $1.02-1.05$ \\
$\begin{array}{l}\text { Cardiovascular disease } \\
\begin{array}{c}\text { Muscle reinforcement } \\
\text { of bronchial stump }\end{array}\end{array}$ & .001 & 1.809 & $1.27-2.57$ \\
\hline
\end{tabular}

$O R$, Odds ratio; $C I$, confidence interval.

Table V. Variables that adversely affected postoperative mortality with univariate analysis

\begin{tabular}{ll}
\hline Significant adverse effect & P value \\
\hline Cardiovascular disease & $<.0001$ \\
Hematologic disease & .005 \\
Preoperative chemotherapy & .01 \\
Lower hemoglobin level & .004 \\
Decreased DLCO, exercise (\% predicted) & .002 \\
Right-sided pneumonectomy & .0006 \\
Reinforcement of bronchial stump & .007 \\
Extended resection & .04 \\
Parenteral crystalloid first $12 \mathrm{~h}$ & .01
\end{tabular}

$D L C O$, Diffusion capacity of lung to carbon monoxide.

erative hours (median 2 units, range 1-18 units). Overall, 100 patients had at least one blood transfusion (median 2 units, range 1-39 units). Median volume of crystalloid solution infused in the first 12 hours, including intraoperatively, was $19.9 \mathrm{~mL} / \mathrm{kg}$ (range $0.96-201.1 \mathrm{~mL} / \mathrm{kg}$ ). Median volume of crystalloid solution infused in the first 24 hours, including intraoperatively, was $28.2 \mathrm{~mL} / \mathrm{kg}$ (range $3.1-109.8 \mathrm{~mL} / \mathrm{kg}$ ).

\section{Results}

Complications occurred in $276(43.2 \%)$ patients (Table II). There were 45 deaths (mortality $7.0 \%$; 95\% CI $5.2 \%-9.3 \%)$. Mortality was $6.9 \%(\mathrm{n}=42)$ for patients with primary lung cancer and $9.4 \%(\mathrm{n}=3)$ for patients with metastatic cancer. Thirty-seven deaths occurred during hospitalization and 8 after hospital dismissal. One $(0.2 \%)$ death occurred intraoperatively. Cause of death was pneumonia/acute respiratory distress syndrome (ARDS) in 8, postpneumonectomy pulmonary edema/ARDS in 7 patients, ARDS in 4, bronchopleural fistula in 4, pulmonary embolus in 4, myocardial infarction in 3, cardiac arrest in 2, respiratory failure in 2, and intraoperative bleeding, stroke, aspiration, torsion of the left ventricle, and sepsis in 1 patient each. Cause of death was unknown in 6 patients. Seventeen (38.0\%) postmortem examinations were performed. Hospitalization ranged from 4 to 146 days (median 7 days). 
Cardiopulmonary complications occurred in 245 patients $(38.3 \%$; 95\% CI $34.6 \%-42.2 \%)$. Factors adversely affecting morbidity with univariate analysis are given in Table III. Those adversely affecting morbidity with multivariate analysis are listed in Table IV. Factors adversely affecting mortality with univariate analysis are given in Table $\mathrm{V}$ and those affecting mortality with multivariate analysis are listed in Table VI. Factors not affecting morbidity or mortality included corticosteroid use, chronic renal failure, diabetes mellitus, cirrhosis, nonpulmonary malignancy, smoking within 8 weeks of pneumonectomy, weight loss, stage, timing of chest tube removal, preoperative total lung capacity (percent predicted), and residual volume (percent predicted).

\section{Discussion}

Pneumonectomy has the highest complication and mortality rate of all elective pulmonary resections. ${ }^{1,2}$ Although our report represents the largest series of consecutive pneumonectomies for cancer from a single institution, comparison with other reports is difficult because statistical analysis and the number of patients vary widely. ${ }^{8-18}$ Nonetheless, many similarities are noted. As with other series, ${ }^{1}$ pulmonary and cardiovascular complications were most frequent and accounted for more than $85 \%$ of all complications. For this reason our morbidity analysis focused mainly on cardiopulmonary complications.

Not uncommonly, patients who require pulmonary resection for lung cancer have pre-existent cardiovascular and/or pulmonary disease. We identified various factors that adversely affected postoperative morbidity and mortality. Most of these variables measured airway obstruction (vital capacity, forced expiratory volume in 1 second, forced vital capacity) and/or impaired gas exchange (diffusion capacity of the lung to carbon monoxide, oxygen saturation, $\mathrm{PaO}_{2}$ ). Like results reported by others, ${ }^{8,9,19}$ our data demonstrated that a decreased diffusion capacity of the lung to carbon monoxide is an independent adverse predictor of postoperative complications.

Pre-existent cardiovascular disease was one of the strongest predictors of morbidity and mortality. Our data confirm the reports of others ${ }^{14,16}$ who demonstrated that the presence of concomitant cardiovascular disease was associated with increased mortality. Although arrhythmias occurred in more than $25 \%$ of our patients, no preoperative risk factors were identified; however, atrial fibrillation was often coexistent with pneumonia and respiratory failure. ${ }^{13,20,21}$

Excess perioperative crystalloid infusion in our patients had an adverse effect on postoperative morbid-
Table VI. Variables that adversely affected postoperative mortality with multivariate analysis

\begin{tabular}{lccc}
\hline Variable & $\mathrm{P}$ value & OR & $95 \%$ CI \\
\hline Hematologic disease & .013 & 5.55 & $1.44-21.5$ \\
Lower hemoglobin level & .003 & 0.78 & $0.66-0.92$ \\
Completion pneumonectomy & .01 & 2.89 & $1.28-6.53$ \\
\hline
\end{tabular}

$O R$, Odds ratio; $C I$, confidence interval.

Table VII. Reported pneumonectomy series

\begin{tabular}{|c|c|c|c|}
\hline First author & Year & Patients & Mortality (\%) \\
\hline Deslauriers $^{10}$ & 1989 & $402 *$ & 5 \\
\hline Wahi ${ }^{11}$ & 1989 & 197 & 7 \\
\hline Romano $^{12}$ & 1992 & $1529 \dagger$ & 11.6 \\
\hline Von Knorring $^{13}$ & 1992 & 200 & 7 \\
\hline Patel $^{14}$ & 1992 & 197 & 8.6 \\
\hline Miller $^{15}$ & 1993 & 153 & 5.2 \\
\hline Ferguson $^{8}$ & 1995 & 92 & 12 \\
\hline Harpole $^{16}$ & 1996 & 136 & 3 \\
\hline Mizushima $^{17}$ & 1997 & 122 & 4.1 \\
\hline Swartz $^{18}$ & 1997 & 92 & 10.9 \\
\hline Mayo & 2001 & 639 & 7.0 \\
\hline
\end{tabular}

*Series from 2 separate medical centers.

$\dagger$ All non-federal acute care hospitals in the state of California.

ity and mortality. Although these data would support the suggestion of others that excess fluid administration is both a significant factor in the genesis of respiratory complications ${ }^{22}$ and an independent predictor of mortality, ${ }^{14,18}$ other studies have found no significant association between fluid administered and the development of pulmonary edema. ${ }^{23,24}$ Because our analysis was retrospective and uncontrolled, we cannot conclude that crystalloid infusion is a contributory factor in postpneumonectomy respiratory failure.

Although we did demonstrate that pre-existent hematologic disease and a lower serum hemoglobin level were associated with increased mortality, we have no explanation for this observation. Of interest, however, Harpole and associates ${ }^{16}$ reported a correlation between a low hematocrit value and the onset of atrial arrhythmias after pneumonectomy.

Even if more than half of our patients underwent an extended or completion pneumonectomy, our mortality of $7 \%$ compares favorably with that reported by others (3\%-12\%) (Table VII). ${ }^{8,10-18,25,26}$ We believe that patient selection is critical in minimizing complications. ${ }^{1}$ It is imperative that the surgeon preoperatively determine whether a patient can tolerate pneumonectomy. The presence of cardiovascular disease should be actively investigated and pre-existent arrhythmias appropriately managed. Similarly, the respiratory status should be 
evaluated and any reversible condition, such as bronchospasm, infection, and smoking, be addressed.

Prevention of complications at the time of operation is key to reducing perioperative mortality. Hemorrhage in our series was responsible for one intraoperative death. Intrapericardial control to prevent intraoperative hemorrhage may be critical in patients requiring completion pneumonectomy or having received preoperative hilar radiation. ${ }^{27,28}$ The bronchial stump also must be managed with meticulous care, avoiding devascularization and excessive length. Our preference is to reinforce the bronchial stump with muscle to reduce dehiscence if the mediastinum and hilum have been previously irradiated. ${ }^{29,30}$ Although our study did demonstrate that bronchial stump reinforcement was adversely associated with mortality, we believe that this is secondary to patient selection because our practice has been to reinforce the stump in those patients most likely to have complications.

We conclude that morbidity and mortality after pneumonectomy for malignant disease are multifactorial. Appropriate selection and meticulous perioperative care are paramount to minimize risks in those patients who require pneumonectomy.

Received for publication May 8, 2000; revisions requested July 11, 2000; revisions received Jan 9, 2001; accepted for publication Jan 10, 2001.

Address for reprints: Claude Deschamps, MD, Division of General Thoracic Surgery, Mayo Clinic and Mayo Foundation, 200 First St, SW, Rochester, MN 55905 (E-mail: deschamps.claude@mayo.edu).

\section{REFERENCES}

1. Ferguson MK. Assessment of operative risk for pneumonectomy. Chest Clin North Am 1999;199:339-51.

2. Ginsberg RJ, Hill LD, Eagan RT, Thomas P, Mountain CF, Deslauriers J, et al. Modern thirty-day operative mortality for surgical resections in lung cancer. $\mathbf{J}$ Thorac Cardiovasc Surg 1983;86:654-8.

3. Snedecor GW, Cochran WG. Statistical methods. Ames [IA]: Iowa State University Press; 1967. p. 100-6.

4. Hollander M, Wolfe DA. Nonparametric statistical methods. New York: John Wiley; 1973. p. 68-75.

5. Snedecor GW, Cochran WG. Statistical methods. 7th ed. Ames [IA]: Iowa State University Press; 1980. p 75-8.

6. Mehta CR, Patel NR. A network algorithm for performing Fisher's Exact Test in rXc contingency tables. J Am Stat Assoc 1983;78:427-34.

7. Walker SH, Duncan DB. Estimation of the probability of an event as a function of several independent variables. Biometrika 1967;54:167-79.

8. Ferguson MK, Reeder LB, Mick R. Optimizing selection of patients for major lung resection. J Thorac Cardiovasc Surg 1995;109:275-83.
9. Bousamra M, Presberg KW, Chammas JH, Tweddell JS, Winton BL, Bielefeld MR, et al. Early and late morbidity in patients undergoing pulmonary resection with low diffusion capacity. Ann Thorac Surg 1996;62:968-75.

10. Deslauriers J, Ginsberg RJ, Dubois P, Beaulieu M, Goldberg M, Piraux M. Current operative morbidity associated with elective surgical resection for lung cancer. Can J Surg 1989;32:335-9.

11. Wahi R, McMurtrey MJ, DeCaro LF, Mountain CF, Ali MK, Smith TL, et al. Determinant of perioperative morbidity and mortality after pneumonectomy. Ann Thorac Surg 1989;48:33-7.

12. Romano PS, Mark DH. Patients and hospital characteristics related to in-hospital mortality after lung cancer resection. Chest 1992;101:1332-7.

13. Von Knorring J, Lepantalo M, Lindgren L, Lindfors O. Cardiac arrhythmias and myocardial ischemia after thoracotomy for lung cancer. Ann Thorac Surg 1992;53:642-7.

14. Patel RL, Townsend ER, Fountain SW. Elective pneumonectomy: factors associated with morbidity and operative mortality. Ann Thorac Surg 1992;54:84-8.

15. Miller JI. Physiologic evaluation of pulmonary function in the candidate for lung resection. J Thorac Cardiovasc Surg 1993;105:347-52.

16. Harpole DH Jr, Liptay MJ, DeCamp MM Jr, Mentzer SJ, Swanson SJ, Sugarbaker DJ. Prospective analysis of pneumonectomy: risk factors for major morbidity and cardiac dysrhythmias. Ann Thorac Surg 1996;61:977-82.

17. Mizushima Y, Noto H, Sugiyama S, Kusajima Y, Yamashita R, Kashii T, et al. Survival and prognosis after pneumonectomy for lung cancer in the elderly. Ann Thorac Surg 1997;64:193-8.

18. Swartz DE, Lachapelle K, Sampalis J, Mulder DS, Chiu RC, Wilson J. Perioperative mortality after pneumonectomy: analysis of risk factors and review of the literature. Can J Surg 1997;40:437-44.

19. Ferguson MK, Little L, Rizzo L, Popovich KJ, Glonek GF, Leff A, et al. Diffusing capacity predicts morbidity and mortality after pulmonary resection. J Thorac Cardiovasc Surg 1988;96:894-900.

20. Krowka MJ, Pairolero PC, Trastek VF, Payne WS, Bernatz PE. Cardiac dysrhythmia following pneumonectomy. Chest 1987;91:490-5.

21. Cardinale D, Martinoni A, Cipolla CM, Civelli M, Lamantia G, Fiorentini $\mathrm{C}$, et al. Atrial fibrillation after operation for lung cancer: clinical and prognostic significance. Ann Thorac Surg 1999;68:1827-31.

22. Van der Werff YD, van der Houwen HK, Heijmans PJM, Duurkens VAM, Leusink HA, van Heesewijk HPM, et al. Postpneumonectomy pulmonary edema. Chest 1997;111:127884.

23. Turnage WS, Lunn JJ. Postpneumonectomy pulmonary edema: a retrospective analysis of associated variables. Chest 1993;103:1646-50.

24. Waller DA, Gebitekin C, Saunders NR, Walker DR. Noncardiogenic pulmonary edema complicating lung resection. Ann Thorac Surg 1993;55:140-3.

25. Silvestri GA, Handy J, Lackland D, Corley E, Reed CE. Specialists achieve better outcomes than generalists for lung cancer surgery. Chest 1998;114:675-80.

26. Harpole DH, DeCamp MM Jr, Daley J, Hur K, Oprian CA, Henderson WG, et al. Prognostic models of thirty-day mortality and morbidity after major pulmonary resection. J Thorac Cardiovasc Surg 1999;117:969-79. 
27. Gregoire J, Deslauriers J, Guojin L, Rouleau J. Indications, risks, and results of completion pneumonectomy. $\mathbf{J}$ Thorac Cardiovasc Surg 1993;105:918-24.

28. McGovern EM, Trastek VF, Pairolero PC, Payne WS. Completion pneumonectomy: indications, complications and results. Ann Thorac Surg 1988;46:141-6.

29. Pairolero PC, Arnold PG, Piehler JM. Intrathoracic transposition of extrathoracic skeletal muscle. J Thorac Cardiovasc Surg 1983;86:809-17.

30. Frytak S, Lee RE, Pairolero PC. Necrotic lung and bronchopleural fistula as complications of therapy in lung cancer. Cancer Invest 1988;6:139-43.

\section{Discussion}

Dr Malcolm M. DeCamp, Jr (Cleveland, Ohio). Pneumonectomy is a disease in and of itself. Because of this, we as surgeons must be convinced that we are substituting this disease for a less favorable one.

Over almost a 13-year experience, these investigators have performed pneumonectomy in 639 patients. To put this information into perspective, it would be important for all of us to know what the denominator is, what percentage of therapeutic resections for lung cancer during this era were pneumonectomies.

Over 13 years, the mortality for pneumonectomy in this institution was $7 \%$. This is certainly within range of others' published experiences. The results, however, are even more impressive if we consider that $23 \%$ of the pneumonectomies were for $\mathrm{T} 3$ or T4 lesions and necessitated resection of associated chest wall, left atrium, carina, diaphragm, superior vena cava, esophageal wall, or aortic wall. I would be interested in a breakdown of the mortality figures for this higher risk group.

Dr Deschamps, 343 of your patients had locally advanced disease as reflected by postoperative resected stages IIIA or IIIB. Despite this, only 285 patients underwent mediastinoscopy. What is your institutional approach to central lesions that are likely to require pneumonectomy?

Despite the fact that more than half of the group had stage IIIA or IIIB disease, only 63 , or roughly $18 \%$, of this highrisk patient group had some form of induction therapy. There is now fairly compelling evidence that multimodal therapy offers a survival advantage for such patients. Has the philosophy of therapy for stage III disease evolved over this same era at the Mayo Clinic?

Perhaps one of the most feared complications and consequences of pneumonectomy is postpneumonectomy empyema and bronchopleural fistula. Postpneumonectomy empyema developed in $5.6 \%$ of your patients, associated with a bronchopleural fistula in two thirds of these patients. Four of the 25 patients with a bronchopleural fistula died. Muscle reinforcement of your bronchial stump was found to be an independent predictor of postoperative morbidity. How many of these patients had empyema or postoperative bronchopleural fistula despite aggressive therapy for their bronchial stump in the operating room?

Finally, the stated objective of this work was to assess for factors affecting morbidity and mortality after pneumonectomy. To do this, you have performed a very exhaustive uni- variable and multivariable analysis looking at a host of factors, and you have defined 3 independent variables that predict morbidity and 3 separate independent variables that predict mortality.

I would have to direct you to some similar prospective work that Harpole and I did in conjunction with the Veterans Affairs Cooperative Group, published in 1999 (J Thorac Cardiovasc Surg 1999;117:969-79), in which we looked at 567 pneumonectomies performed between 1991 and 1995. We also found, in a multivariable analysis, 8 distinct preoperative factors predictive for 30-day mortality and a separate 8 distinct variables predictive for 30 -day morbidity. The goal of our study was to create a prognostic model to allow practitioners to assess risk and counsel patients accordingly.

How would you propose to use the specific data that you have gleaned from your work to better select patients for pneumonectomy? For example, as advanced age was a predictor of morbidity in your series, is there a particular cutoff above which you might not recommend surgery? Similarly, preoperative anemia was predictive of postoperative mortality in your experience. Would preoperative transfusion enhance the survivability of these patients?

Dr Deschamps. Thank you very much, Dr DeCamp, for your kind review.

Pneumonectomy in our institution constitutes about $15 \%$ of all pulmonary resections for cure. We have not broken down our morbidity by stage.

As you probably know, mediastinoscopy has not been used routinely in our institution. As we have increasingly become a part of the community that does protocols, we have seen ourselves doing mediastinoscopy more frequently in the past 10 years. Right now we do use mediastinoscopy in patients who are not on protocol if they have abnormal lymph nodes on computed tomographic scan or disease that is likely to need a pneumonectomy. We also use mediastinoscopy in patients whose condition is compromised and whom we think will not tolerate a radical resection such as a pneumonectomy.

The role of preoperative treatment has evolved in our institution, too. Like other institutions, we are embarking on more and more protocols for preoperative treatment. At this point, we do think that preoperative treatment has its role in patients with $\mathrm{N} 2$ disease.

We are still trying to examine the data, but we have not been successful in preventing all bronchopleural fistulas by using prophylactic muscle flaps. We do not reinforce the bronchial stump in a randomized fashion, so it is not certain that using a muscle will have a significant effect in preventing bronchopleural fistula. Many of our patients are considered at risk for bronchopleural fistula. Pairolero started using prophylactic muscle a long time ago and still favors it. Our group concurs, of course, that the patient who has had radiation, chemotherapy, or a significant pleural space infection might benefit from reinforcement with a muscle, but we have seen failures and we are still evaluating the data.

Finally, I do not know how I would propose using a cutoff, since using a cutoff for every or any variable is a subjective 
and arbitrary decision. Who am I to say that a patient who is 69 years old should not have a pneumonectomy only because in our study increased age has been a factor? Actually, our mortality is not significantly higher between the group younger than 70 years and the group older than 70 years. Mortality is, of course, higher, but it is not significantly higher. We do not know yet whether a hemoglobin value of 12 $\mathrm{g} / \mathrm{dL}$ is better than $9 \mathrm{~g} / \mathrm{dL}$ or whether an age of 70 years is better than 75 years or a $\mathrm{PO}_{2}$ of $65 \mathrm{~mm} \mathrm{Hg}$ is better than $59 \mathrm{~mm}$ $\mathrm{Hg}$ ? We are not going to try to establish cutoff criteria. We do not have survival criteria, but certainly mediastinoscopy is an operation that is needed in many patients.

Bronchoplastic surgery is not applicable to all patients. Pneumonectomy is an operation that thoracic surgeons should not fear but rather should do with confidence when it is needed.

Dr Carolyn E. Reed (Charleston, SC). The number of patients and the consistency in this report add significantly to the literature. Many of the findings are not surprising, but some of them are intriguing. I was intrigued by the finding that the hemoglobin level was an important factor for postoperative mortality. It is certainly something that we can do something about ahead of time. Knowing your data now, would you do something about it?

I was also dismayed that $47 \%$ of your patients had stage IIIA disease. We certainly would avoid doing a pneumonectomy in that group at our institution, if possible, and would do a very thorough metastatic survey. What was your standard for metastatic survey? Also, what was the overall survival in this particular group of patients who underwent pneumonectomy?

Multivariate analysis showed that bronchial stump reinforcement affected morbidity. Could you break that down? We know that patients with right pneumonectomies after chemotherapy/radiation are a particularly high-risk group. What was the result in this subset of patients in your hands?

Dr Deschamps. Dr Reed, thank you for your comments.

A patient who comes to a pneumonectomy with a hemoglobin of $8 \mathrm{~g} / \mathrm{dL}$ will receive a transfusion before the operation, and I will not feel too uncomfortable. Given our data, I would prefer to do the transfusion before the operation, on an outpatient basis, rather than during the operation.

At the present time at the Mayo Clinic we do not do a workup for metastatic disease unless there are abnormal physical findings, abnormal subjective findings, and abnormal laboratory findings, such as elevated hepatic enzymes, and unless there are findings on the computed tomographic scan. Every patient will have a physical examination, regular blood tests, bone enzyme studies, and liver enzyme studies, and the computed tomographic scan will cover the upper part of the abdomen and the chest. With this regimen, we think that we adequately evaluate most patients. Of course, we might be wrong and time will tell. We do not have survival data.

For the purpose of this study, we did not break down the survival by stage and by chemoradiation therapy.

Dr Denise Ouellette (Montreal, Quebec, Canada). I have
2 questions: First, what was the mortality rate of the patients having right pneumonectomies? Second, what type of lesion did the patients with stage IA disease have to require a pneumonectomy?

Dr Deschamps. Our mortality was higher for right pneumonectomy, but not by much-about $9 \%$ versus $6 \%$.

I do not have the breakdown on stage of disease, but the higher the stage, the more complications and the more mortalities. However, the difference was not statistically significant.

Dr John R. Benfield (Los Angeles, Calif). This is a wonderful paper to illustrate that statistical analysis at times does not really help to interpret results. It reminds me of the story about the Philadelphia medical examiner in the early days of intravenous fluid therapy, saying that such treatment is bad because all the patients that he was examining post mortem had been given intravenous fluids. My point is that it is erroneous to refer to the use of muscle flaps to protect the bronchial stump as a "mortality factor." We use muscle flaps when the patient is at higher-than-usual risk for bronchopleural fistula. Thus, the interesting facts we have heard are less meaningful than stated, and they must not be interpreted as evidence to suggest that muscle flaps should not be used to cover bronchial stumps after pneumonectomies.

I wanted to ask you about the long-term outcome after pneumonectomies for stage III cancers in the hope that you would say they are now even better than they were in an article in The Journal of Thoracic and Cardiovascular Surgery by Peter Pairolero from your institution perhaps 9 or more years ago. I believe the long-term survival after resections of stage III cancers was about $26 \%$ without induction therapy. You already said that you do not have the information about which I was going to ask, and so I simply call attention to the fact that those results without induction therapy are about the same as the current best results after induction therapy.

Dr Deschamps. Dr Benfield, thank you for your comments. I am still waiting to be praised for our $97 \%$ lymphadenectomy rate. Now that I have said that, we decided to look at the muscle data and did find that it was a factor of morbidity. Of course, patients treated with muscle flaps were sick patients, and we covered that topic in the discussion section. The data were there, and we had to find an explanation. Statistics do have their limits, but we still favor doing muscle flaps in all patients whom we think are at risk of having a fistula. A prospective study would be useful.

Dr Robert L. Thurer (Boston, Mass). As the Association's representative to the American Association of Blood Banks, I feel compelled to make some comments about anemia. Although it may be true that anemia is a marker for worse outcome and correction of anemia is valuable in patients having pneumonectomy, it is quite another thing to say that correcting the anemia will eliminate that as a marker for a bad outcome. Anemia may represent a poor physiologic status related to tumor size, occult metastatic disease, or other factors that may affect outcome. We should not leap to the conclusion that correction of anemia will eliminate preoperative anemia as an adverse factor. 